Document downloaded from:

http://hdl.handle.net/10251/145210

This paper must be cited as:

Fajardo, JE.; Carlevaro, CM.; Vericat, F.; Berjano, E.; Irastorza, RM. (12-2). Effect of the trabecular bone microstructure on measuring its thermal conductivity: A computer modelingbased study. Journal of Thermal Biology. 77:131-136.

https://doi.org/10.1016/j.jtherbio.2018.08.009

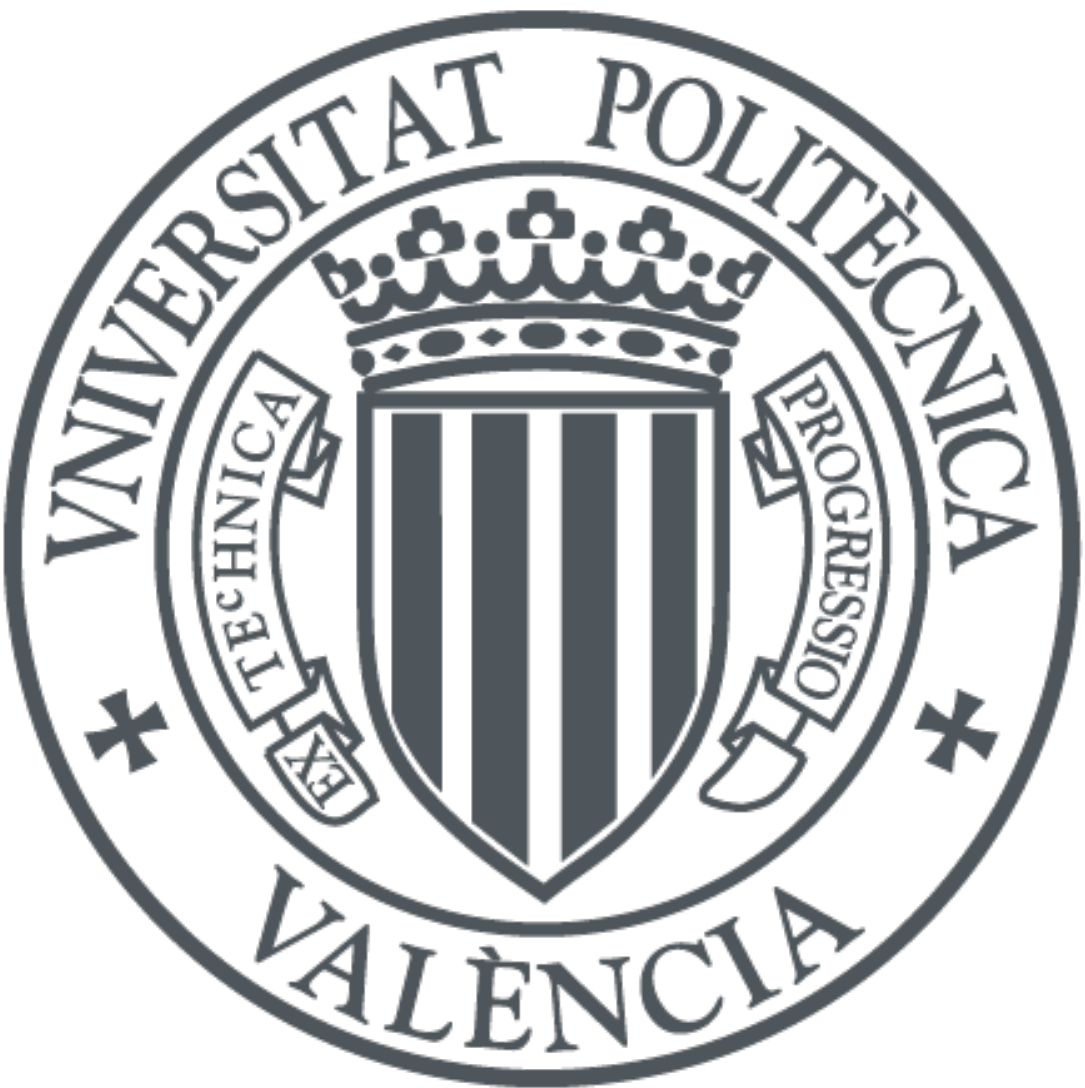

The final publication is available at

https://doi.org/10.1016/j.jtherbio.2018.08.009

Copyright Elsevier

Additional Information 


\section{Effect of the trabecular bone microstructure on measuring its thermal conductivity: a computer modeling-based study}

Jesús E. Fajardo ${ }^{1}$, C. Manuel Carlevaro ${ }^{1,2}$, Fernando Vericat ${ }^{1}$, Enrique Berjano ${ }^{3}$, Ramiro M Irastorza ${ }^{1,4}$

${ }^{1}$ Instituto de Física de Líquidos y Sistemas Biológicos (CONICET), La Plata, Argentina

${ }^{2}$ Universidad Tecnológica Nacional, Facultad Regional Buenos Aires, Buenos Aires, Argentina

${ }^{3}$ BioMIT, Department of Electronic Engineering, Universitat Politècnica de València, Valencia, Spain

${ }^{4}$ Instituto de Ingeniería y Agronomía, Universidad Nacional Arturo Jauretche, Argentina

Corresponding author: Dr. Ramiro M Irastorza, Instituto de Física de Líquidos y Sistemas Biológicos (CONICET), Calle 59 No 789, B1900BTE La Plata, Argentina. Phone: +54-2214233283, Fax:+54-221-4257317. E-mail: rirastorza@iflysib.unlp.edu.ar

Financial support: This work was supported by a grant from the "Agencia Nacional de Promoción Científica y Tecnológica de Argentina” (Ref. PICT-2016-2303), and by the Spanish "Programa Estatal de Investigación, Desarrollo e Innovación Orientada a los Retos de la Sociedad" under Grant TEC2014-52383-C3-R (TEC2014-52383-C3-1-R). 


\begin{abstract}
The objective of this work is to quantify the relation between the value of the effective thermal conductivity of trabecular bone and its microstructure and marrow content. The thermal conductivity of twenty bovine trabecular bone samples was measured prior to and after defatting at 37,47 , and $57^{\circ} \mathrm{C}$. Computer models were built including the microstructure geometry and the gap between the tissue and measurement probe. The thermal conductivity $(\mathrm{k})$ measured was $0.39 \pm 0.06 \mathrm{Wm}^{-1} \mathrm{~K}^{-1}$ at $37^{\circ} \mathrm{C}$, with a temperature dependence of $+0.2 \%{ }^{\circ} \mathrm{C}^{-1}$. Replacing marrow by phosphate-buffered saline (defatting) increased both the computer simulations and measurement results by $0.04 \mathrm{Wm}^{-1} \mathrm{~K}^{-1}$. The computer simulations showed that $\mathrm{k}$ increases by $0.02-0.04 \mathrm{Wm}^{-1} \mathrm{~K}^{-1}$ when the model includes a gap filled by phosphate-buffered saline between the tissue and measurement probe. In the presence of microstructure and fatty red marrow, $\mathrm{k}$ varies by $\pm 0.01 \mathrm{Wm}^{-1} \mathrm{~K}^{-1}$ compared with the case considering matrix only, which suggests that there are no significant differences between cortical and trabecular bone in terms of $\mathrm{k}$. The computer results showed that the presence of a gap filled by phosphate-buffered saline around the energy applicator changes maximum temperature by $<0.7^{\circ} \mathrm{C}$, while including the bone microstructure involved a variation of $<0.2 \mathrm{~mm}$ in the isotherm location. Future experimental studies on measuring the value of $\mathrm{k}$ involving the insertion of a probe into the bone through a drill hole should consider the bias found in the simulations. Thermal models based on a homogeneous geometry (i.e. ignoring the microstructure) could provide sufficient accuracy.
\end{abstract}

KEY WORDS: computer model, thermal conductivity, trabecular bone 


\section{Introduction}

Computer modeling is widely employed to solve problems involving the thermal response of biological tissues in general and bone in particular. Computer models have been proposed to evaluate the heat transfer in bone tissues resulting from thermal ablation (Irastorza et al 2017, Matschek et al 2017), mechanical drilling (Davidson and James 2003), or associated with bone cement in joint prosthesis (Hansen 2003, Li et al 2003). To improve the accuracy of these models, it is crucial to thermally characterize the bone tissues as far as possible, with special attention to their thermal conductivity $(\mathrm{k})$, which determines the ability of the tissue to conduct heat. The models generally use data from different databases (Hasgall et al 2015), which in turn, review the available scientific literature. Most of these databases consider that tissues are homogeneous. While this assumption may be valid for certain tissues, the porosity of trabecular bone (also known as cancellous bone) could significantly affect its thermal conductivity, as is the case with its electrical properties (Sierpowska et al 2006, Sierpowska et al 2007). As the thermal conductivity of trabecular bone and its relationship with its microstructure and marrow content is still poorly understood, our objective was to study the effects of the microstructure and marrow content on its thermal conductivity. In particular: 1) to measure the this conductivity in samples of bovine trabecular bone and study their temperature dependence within a broad range $\left.\left(37^{\circ} \mathrm{C}-57^{\circ} \mathrm{C}\right) ; 2\right)$ to use computer simulations to study the effects of bone marrow content and microstructure on the values of thermal conductivity; and 3) to quantify the error associated with the gap between the tissue sample and the thermistor-based conductivity measurement probe. 


\section{Materials and methods}

\subsection{Samples preparation}

Twenty approximately cylindrical bovine trabecular bone samples (10 mm long, $16 \mathrm{~mm}$ diameter) were obtained from the femur head of five animals from the local slaughterhouse within less than 24 hours post-mortem (stored at $4^{\circ} \mathrm{C}$ ). The samples were machined using ad hoc tools. During the cutting process, they were moistened with phosphate-buffered saline (PBS) to avoid high temperatures and then kept at $4{ }^{\circ} \mathrm{C}$ overnight in sealed plastic tubes containing PBS. The next day they were thawed immediately prior to measurement. After measuring the thermal conductivity of each sample, the marrow was removed from the samples, first by ultra-sonication in a 2\% tergazyme solution using a B-220 Ultrasonicator (Branson Ultrasonics Americas, Danbury, CT, USA), as in Gee et al (2015), and then cleaned under a gentle flow of distilled water. The samples were cleaned until being sufficiently translucent to make the trabecular structure visible. They were then stored in PBS solution for eight hours, when the thermal conductivity of the defatted samples was measured again.

\subsection{Porosity assessment}

The porosity of the sample was estimated after extracting marrow from high-resolution pictures obtained with a USB-microscope PCE-MM200 (PCE Instruments, Southampton, UK) with $200 \times$ magnification and $1280 \times 1024$ pixels. The sample pores on the side where the thermistor was inserted were detected by modified routines from Van der Walt et al (2014). Fig. 1B shows an example of an image which was processed in order to estimate the porosity degree by considering the trabecular matrix and marrow phases. 


\subsection{Thermal conductivity measurements}

The same experimental setup was used as in Valvano et al (1985) to measure the thermal properties of in vivo tissues with minimal invasion by means of a self-heated thermistor. Briefly, an electronic feedback circuit applies variable power $P(t)$ to a thermistor in contact with the tissue to maintain the average thermistor temperature at a predefined constant ( $\left.\mathrm{T}_{\text {HIGH }}\right)$. The power required to maintain $\mathrm{T}_{\text {HIGH }}$ includes a steady state term and a transient term. In theory, the applied power can be approximated by:

$$
P(t)=A+B \cdot t^{-1 / 2}
$$

where A and B are parameters related to thermal conductivity (k) and diffusivity $(\alpha)$, respectively. These parameters have different values in the different samples. A previous calibration with two media of known thermal properties of agar gel and glycerol was performed to obtain the value of the constants associated with the specific setup of sample and thermistor. A $1 \mathrm{k} \Omega, 1.5 \mathrm{~mm}$ diameter 120-102EAJ-Q01 thermistor (Honeywell, Morris Plains, NJ, USA) was used (see Fig. 1A). The electronic signal of the power evolution was digitalized by a USB-1608GX data acquisition device (Measurement Computing Corporation, Norton, MA, USA), which was also used to control the electronic feedback circuit. A $1.5 \mathrm{~mm}$ diameter x $3 \mathrm{~mm}$ deep hole was drilled in the centre of each sample, into which the thermistor was carefully placed (see Fig. 1B). The sample was then completely submerged in PBS and maintained at baseline temperature $\left(\mathrm{T}_{\text {LOw }}\right)$ by a LAUDA RE106 cryostat (Lauda Brikmann, Lauda-Königshofen, Germany). Three sets of measurements were performed at different $\mathrm{T}_{\mathrm{LOw}}\left(37,47\right.$, and $\left.57^{\circ} \mathrm{C}\right)$. During each set, the self-heating technique consisted of raising $\mathrm{T}_{\mathrm{HIGH}}-\mathrm{T}_{\mathrm{LOW}}=4^{\circ} \mathrm{C}$ above $\mathrm{T}_{\mathrm{LOW}}$ and recording the evolution of the power needed to do so. Thermal conductivity was assumed to be constant within the 
range from $\mathrm{T}_{\mathrm{LOW}}$ to $\mathrm{T}_{\mathrm{HIGH}}$. Thermal conductivity was obtained at 37,47 , and $57^{\circ} \mathrm{C}$ before and after extracting the marrow content from the samples.

\subsection{Computer modeling}

Figure 1B shows an example of a defatted sample. The thermistor was inserted into the central hole to measure the thermal conductivity of the sample. This image was also used to build a trabecular bone computer model (see Fig. 1C), whose geometry included zones of marrow and matrix, along with a gap between thermistor and tissue, which was expected to fill with PBS during the measuring process. The image employed to build the model (Fig. 1B) was representative of other samples in terms of the proportion of marrow volume to total volume $(24 \pm 9 \%)$, and gap thickness $(0.20 \pm 0.09 \mathrm{~mm})$. The model shown in Fig. $1 \mathrm{~B}$ has a mean gap of $0.18 \mathrm{~mm}$ with maximum and minimum of $0.5 \mathrm{~mm}$ and $0.05 \mathrm{~mm}$, respectively.

The model was used to estimate computationally the overall value of thermal conductivity of the entire sample, $\mathrm{k}_{\mathrm{eff}}$, which is referred to as 'effective thermal conductivity' in the present paper. This allowed the effect of bone marrow content and the gap on the values of $\mathrm{k}_{\mathrm{eff}}$ to be assessed. From the computational point of view, the central hole is not part of the domain, and its outer boundary is really the inner boundary of the model $\left(\mathrm{r}_{\mathrm{i}}=0.75 \mathrm{~mm}\right)$. The outer model boundary $\left(\mathrm{r}_{\mathrm{o}}\right)$ was obtained by a sensitivity analysis in which this parameter was progressively increased until the calculated $k_{\text {eff }}$ values varied by less than $0.01 \mathrm{Wm}^{-1} \mathrm{~K}^{-1}$.

The 2D image shown in Fig. 1C was extruded to create a 3D model of a cylinder with height L. Although the value of $\mathrm{L}$ is in fact irrelevant in the context of the study (as the computational estimation of $k_{\text {eff }}$ does not depend on $L$ ), its value was chosen to match the 
computational and measurement results in terms of applied stationary power (parameter A in Eq. (1)). The value of $\mathrm{L}$ was $1.5 \mathrm{~mm}$, which corresponded to an applied power of $\mathrm{A}=8.9$ $\mathrm{mW}$.

The model was based on steady heat conduction and was solved numerically using a finite element code based on FEniCS package (Logg et al 2012). The governing equation was:

$\nabla \cdot k \nabla T=0$

where $\mathrm{k}$ is the thermal conductivity and $\mathrm{T}$ is the temperature, both being functions of space. A boundary condition of constant temperature $\mathrm{T}_{\mathrm{HIGH}}$ was set at the inner boundary $\left(\mathrm{r}_{\mathrm{i}}\right)$ to simulate the performance of the self-heating thermistor during the thermal measurements, while the temperature at the outer boundary was fixed at $\mathrm{T}_{\mathrm{LOW}}$.

The model mesh was heterogeneous, with a finer mesh size at the porous interfaces and the central hole, where the highest thermal gradients were expected. All the mesh elements used were linear and triangular. The size of the finest mesh and the optimal time-step were estimated by a sensitivity analysis on the same lines as that used for the outer geometry dimensions.

\subsection{Tissues characteristics}

Table 1 shows the thermal conductivities of the materials used in the model obtained from the database in Hasgall et al (2005), which reviews the scientific literature on tissue characteristics. In the case of yellow and red bone marrow, the lack of available data prevented working with a specific range.

According to Hasgall et al (2005), the thermal conductivity (k) of trabecular bone ranges from 0.29 to $0.36 \mathrm{Wm}^{-1} \mathrm{~K}^{-1}$. This range is based on three studies: two on bovine tissue 
(Calttenburg et al 1975, Collins et al 2004) and one on human tissue (Biyikli et al 1986).

Calttenburg et al (1975) measured trabecular bone under two conditions: intact

$\left(0.25 \mathrm{Wm}^{-1} \mathrm{~K}^{-1}\right)$ and defatted $\left(0.167 \mathrm{Wm}^{-1} \mathrm{~K}^{-1}\right)$; in the latter condition, marrow was replaced by air. Collins et al (2004) is really simulation-based and takes its data from Duck (1990) and so did not contribute much to our study. Biyikli et al (1986) reported a k value of $0.3 \mathrm{Wm}^{-1} \mathrm{~K}^{-1}$, and found that this value was practically the same for trabecular and cortical bone.

Hasgall et al (2005) reported the $\mathrm{k}$ range of cortical bone between 0.3 and $0.36 \mathrm{Wm}^{-1} \mathrm{~K}^{-1}$. This range is based on three studies, all on human tissue (Biyikli et al 1986; Collins et al 2004, McIntosh and Anderson 2010). In addition to the database, we also found some studies which more or less confirmed this range. For instance, El-Brawany et al (2009) reported identical values to Biyikli et al (1986), while Bowman (1981) (also on human tissue) found a range between 0.373 a $0.496 \mathrm{Wm}^{-1} \mathrm{~K}^{-1}$. Davidson and James (2000) reported a value of $\sim 0.54 \mathrm{Wm}^{-1} \mathrm{~K}^{-1}$ in bovine samples, which seems to be in agreement with the highly local measurement performed by Zhang et al (2014).

Hasgall et al (2005) only report a red marrow value $\left(0.28 \mathrm{Wm}^{-1} \mathrm{~K}^{-1}\right)$ obtained from McIntosh and Anderson (2010). This value was really estimated using a mathematical expression which relates $\mathrm{k}$ with water content, also obtained from Copper and Trezek (1971).The yellow marrow value provided by Hasgall et al (2005) is taken from McIntosh and Anderson (2010), who simply assign a porcine fat tissue value of $0.19 \mathrm{Wm}^{-1} \mathrm{~K}^{-1}$, which is not very conclusive. The Poppendiek et al database (1967) also reports a value of 0.22 $\mathrm{Wm}^{-1} \mathrm{~K}^{-1}$ for bovine marrow, although they do not clarify whether it is for red or yellow.

\subsection{Computer simulations}


We conducted different simulations to determine the causes of the dispersion of the $\mathrm{k}$ values in the literature for trabecular bone. In all the simulations the bone matrix (see Fig. 1C) was considered to have the properties of cortical bone, i.e. a k ranging from 0.3 and $0.36 \mathrm{Wm}^{-1} \mathrm{~K}^{-1}$. The 'bone marrow' and 'gap' subdomains were assumed to have different $\mathrm{k}$ values that depended on the purpose of each simulation. Table 2 shows the simulations map and how different values of $\mathrm{k}$ were assigned to each subdomain.

\section{Results}

\subsection{Experimental results}

Table 3 shows the values of the measured thermal conductivity $\left(\mathrm{k}_{\text {meas }}\right)$ at three temperatures for two conditions. The mean value of $\mathrm{k}$ for non-defatted samples at $37^{\circ} \mathrm{C}$ was $0.39 \pm 0.06$ $\mathrm{Wm}^{-1} \mathrm{~K}^{-1}$. Regardless of the conditions (defatted vs. non-defatted), $\mathrm{k}_{\text {meas }}$ increased with temperature. The best-fit line showed a slope of $+0.2 \%{ }^{\circ} \mathrm{C}^{-1}$ (see Fig. 2). When fat was replaced by PBS, $\mathrm{k}_{\text {meas }}$ increased from $\sim 0.39$ to $\sim 0.43 \mathrm{Wm}^{-1} \mathrm{~K}^{-1}$.

\subsection{Computational results}

The sensitivity analysis resulted in an outer dimension of $r_{0}=3.8 \mathrm{~mm}$. Table 2 shows the computed values for the thermal conductivity ( $\left.k_{\text {eff }}\right)$ for each case. In cases \#1 and \#2, the gap subdomain was assumed to be cortical bone, which means that there is no gap. While case \#1 considered a marrow composed mostly of lipids (yellow marrow), case \#2 considered a marrow with predominance of hematopoietic cells (red marrow). Compared to cortical bone (in which all was matrix), the inclusion of a fatty marrow slightly reduced $\mathrm{k}_{\text {eff }}$ $\left(\sim 0.01 \mathrm{Wm}^{-1} \mathrm{~K}^{-1}\right)$. In contrast, the inclusion of red marrow slightly increased $\mathrm{k}_{\mathrm{eff}}(\sim 0.01$

$\mathrm{Wm}^{-1} \mathrm{~K}^{-1}$ ). In order to evaluate the highest values found in the literature for cortical bone 
conductivity (Davidson and James, 2000; Zhang et al. 2014), we re-simulated cases \#1 and \#2 assuming $\mathrm{k} \sim 0.54 \mathrm{Wm}^{-1} \mathrm{~K}^{-1}$ for the gap and matrix domains. These simulations provided values of effective thermal conductivity of 0.50 and $0.52 \mathrm{Wm}^{-1} \mathrm{~K}^{-1}$, for yellow and red marrow, respectively (results not shown in Table 2). Cases \#3, \#4 and \#5 considered cortical bone, trabecular bone with yellow marrow, and trabecular bone with red marrow, respectively, including a gap filled by PBS. Including this gap always increased $\mathrm{k}_{\mathrm{eff}}$, which ranged from $0.04 \mathrm{Wm}^{-1} \mathrm{~K}^{-1}$ in the case of cortical bone, to $\sim 0.02 \mathrm{Wm}^{-1} \mathrm{~K}^{-1}$ in the case of trabecular bone. Case \#6 mimicked a situation in which marrow was replaced by air, in which $\mathrm{k}_{\text {eff }}$ fell to around $0.05 \mathrm{Wm}^{-1} \mathrm{~K}^{-1}$. We also employed the computer model to try to interpret the measurements. For this, case \#7 modeled a situation in which marrow was replaced by PBS (defatted sample) and also included a gap filled with PBS. When this was done, $\mathrm{k}_{\text {eff }}$ increased from

0.33-0.39 $\mathrm{Wm}^{-1} \mathrm{~K}^{-1}$ (case \#5, assuming that our intact samples contained mainly red marrow) to $0.37-0.43 \mathrm{Wm}^{-1} \mathrm{~K}^{-1}$. These values are in close agreement with the mean values obtained from the measurements, which increased from $0.39 \mathrm{Wm}^{-1} \mathrm{~K}^{-1}$ to $0.43 \mathrm{Wm}^{-1} \mathrm{~K}^{-1}$. Finally, the model was used to study the impact of the gap on the temperature distributions created in the bone during thermal procedures, e.g. therapeutic treatments. In this case the temperature of the probe (inserted in the hole) was modeled to rise to $50^{\circ} \mathrm{C}$ to highlight any possible differences and mimic a high-temperature therapeutic procedure. Figure 3 shows the differences in temperature distribution between the cases without (\#1) and with a gap (case \#4) (even though we simulated all the cases, these simulations showed the biggest differences). The plots show two interesting issues: first, the isotherms of both cases differed by less than $0.2 \mathrm{~mm}$ (see Fig. 3A and 3B) and $0.7^{\circ} \mathrm{C}$. Secondly, the inclusion of the 
microstructure in the model (i.e. marrow areas surrounded by cortical matrix) has practically no effect on the isotherms' location, i.e. they keep their circular distribution.

\section{Discussion}

This study explored the effect of microstructure and marrow content on the thermal conductivity of trabecular bone. Firstly, we measured the thermal conductivity in samples of bovine trabecular bone and studied their temperature dependence within a broad range $\left(37^{\circ} \mathrm{C}-57^{\circ} \mathrm{C}\right)$. The value found at $37^{\circ} \mathrm{C}\left(0.39 \pm 0.06 \mathrm{Wm}^{-1} \mathrm{~K}^{-1}\right)$ is slightly above the range reported in Hasgall et al (2005): $0.29-0.36 \mathrm{Wm}^{-1} \mathrm{~K}^{-1}$. The computer results (discussed below) suggest that this discrepancy may be partially due to the presence of a gap filled by PBS around the measurement probe. The temperature dependence of all the defatted and non-defatted samples was around $+0.2 \%{ }^{\circ} \mathrm{C}^{-1}$, which agrees with that reported previously for most tissues (Rossmann and Haemmerich 2014, Valvano et al 1985) and consistently matched the temperature coefficient of water. The higher $\mathrm{k}_{\text {meas }}$ observed when fat was replaced by PBS (from $\sim 0.39$ to $\sim 0.43 \mathrm{Wm}^{-1} \mathrm{~K}^{-1}$ ) can be perfectly explained by the higher PBS k value $\left(0.65 \mathrm{Wm}^{-1} \mathrm{~K}^{-1}\right)$ as compared to marrow $\left(0.19-0.28 \mathrm{Wm}^{-1} \mathrm{~K}^{-1}\right)$. This result allowed us to quantify this increase $\left(+0.04 \mathrm{Wm}^{-1} \mathrm{~K}^{-1}\right)$ for a typical sample, as shown in Fig. $1 \mathrm{~A}$.

Computer simulations were conducted to explore the effects of bone marrow content and microstructure on the thermal conductivity values. When the model included details of the microstructure and (fatty and red) marrow content, thermal conductivity increased by $\sim 0.01 \mathrm{Wm}^{-1} \mathrm{~K}^{-1}$ over that of cortical bone (in which all is matrix and marrow is absent). This could explain why the reported values for trabecular bone $\left(0.29-0.36 \mathrm{Wm}^{-1} \mathrm{~K}^{-1}\right)$ are within the values reported for purely cortical bone $\left(0.3-0.36 \mathrm{Wm}^{-1} \mathrm{~K}^{-1}\right)$, suggesting that 
there are no significant differences between both bone tissue types. Although the greater degree of porosity (and therefore higher concentration of adipose/red tissue) could be responsible for the greater difference between cortical and trabecular bone in terms of thermal conductivity, the presence of fat or red cells in the marrow seems to have the opposite effect, and hence confirms that there should be no great difference between cortical and trabecular bone in terms of thermal conductivity.

The simulations were also able to quantify the error associated with the gap between tissue sample and thermistor-based probe. The inclusion of a PBS-filled gap increased $k_{\text {eff }}$ by $0.02-0.04 \mathrm{Wm}^{-1} \mathrm{~K}^{-1}$. This finding is important since it helps to estimate the measurement error associated with effective thermal conductivity of bone due to the drilling gap. It also suggests that this error is a systematic positive deviation due to the higher thermal conductivity of the PBS between probe and sample. In fact, it could explain the difference between our results $\left(0.39 \pm 0.06 \mathrm{Wm}^{-1} \mathrm{~K}^{-1}\right)$ and the values reported in the literature (0.29 $0.36 \mathrm{Wm}^{-1} \mathrm{~K}^{-1}$, Hasgall et al (2005)). Experimental studies measuring thermal conductivity by inserting a probe into the bone should take these findings into account. It is also reasonable to expect the deviation to increase with gap thickness. The gap should be as small as possible, or its thickness should be quantified, in order to correct it according to our computer results.

We also simulated a situation in which marrow was replaced by air. In this case, thermal conductivity dropped to around $0.05 \mathrm{Wm}^{-1} \mathrm{~K}^{-1}$, which is exactly the opposite to the effect of including a gap filled with PBS. Here, a material with low thermal conductivity (air) is distributed spatially throughout the entire sample (occupying the space previously occupied by the marrow). This result is partially in agreement with the findings of Clattenburg et al 
(1975). While they reported a drop of $0.08 \mathrm{Wm}^{-1} \mathrm{~K}^{-1}$ in $\mathrm{k}$ when marrow was replaced by air, our simulations showed a reduction of up to $0.06 \mathrm{Wm}^{-1} \mathrm{~K}^{-1}$.

Some of the simulations mimicked the measurement conditions of a defatted sample (marrow replaced by PBS) with the gap filled with PBS. Replacing marrow by PBS raised thermal conductivity from $0.33-0.39 \mathrm{Wm}^{-1} \mathrm{~K}^{-1}$ to $0.37-0.43 \mathrm{Wm}^{-1} \mathrm{~K}^{-1}$ in the computer simulations and from $0.39 \mathrm{Wm}^{-1} \mathrm{~K}^{-1}$ to $0.43 \mathrm{Wm}^{-1} \mathrm{~K}^{-1}$ in the measurements. The good agreement between the computer and measurement results thus validates the proposed computer modeling technique and its results.

The computer results suggest that the effect of the gap around the energy applicator during hyperthermic procedures is negligible $\left(<0.7^{\circ} \mathrm{C}\right)$ when the gap is filled with PBS. This is important from the clinical point of view, since some thermal therapies, such as radiofrequency ablation of bone tumors, involve inserting a needle-like electrode through a biopsy cavity. Our results suggest that when the gap is completely full of PBS, the temperature distributions are practically the same as those obtained without a gap. This confirms the need to inject PBS into the cavity to evacuate any air around the electrode that could impede the thermal treatment (Kuyumcu et al 2017).

We also found that the bone microstructure (i.e. the presence of marrow surrounded by cortical matrix) has practically no effect on the isotherm location $(<0.2 \mathrm{~mm})$. From a modeling of point of view, this suggests that it is not really necessary to include the geometry of the microstructure in the model. In other words, the difference between matrix and marrow is not enough to produce a temperature distribution significantly different to the case of homogeneous tissue (which has perfectly concentric isotherms). 


\subsection{Limitations of the study}

It is known that cooling the samples can significantly affect their electrical properties (Sierpowska et al 2006, Saha and Williams 1988) and thermal conductivity. In order to minimize these effects and to improve the comparison between samples, our study considered a carefully standardized method in which all the samples spent the same time in the refrigerator, processing, and PBS solution.

The model employed for the computer modeling was based on a 2D image, although the trabecular bone microstructure is inherently three-dimensional and the trabeculae have different shapes, sizes, and orientations. The model proposed here is composed of two media (matrix and bone marrow) and a gap filled with PBS. The difference between thermal conductivities of both media is not large. For example, if we consider 0.54 $\mathrm{Wm}^{-1} \mathrm{~K}^{-1}$ for bone matrix and $0.19 \mathrm{~W} \mathrm{~m}^{-1} \mathrm{~K}^{-1}$ for bone marrow, the former is 2.84 times higher than the latter (the highest difference reported in the literature between these two media), and gives a value of effective conductivity of approximately $0.50 \mathrm{~W} \mathrm{~m}^{-1} \mathrm{~K}^{-1}$ for the model shown in Fig. 1C. When we compared this simulation to another with an isotropic medium (simulations not shown here) with the same effective thermal conductivity (0.50 W $\mathrm{m}^{-1} \mathrm{~K}^{-1}$ ), there was practically no effect on the position of the isotherms. It can therefore be inferred that the differences between trabeculae and marrow conductivities is not high enough to cause a notable deviation from an isotropic medium, and that the 2D model provides sufficiently accurate results.

We performed a simulation considering the highest contrast cited above $\left(\mathrm{k}=0.54 \mathrm{~W} \mathrm{~m}^{-1} \mathrm{~K}^{-}\right.$

${ }^{1}$ for the bone matrix, and $\mathrm{k}=0.19 \mathrm{~W} \mathrm{~m}^{-1} \mathrm{~K}^{-1}$ for the yellow bone marrow), which showed that it had practically no effect on the position of the isotherms (Fig. R1 (C)) as compared to an isotropic medium (with the same effective thermal conductivity). 


\section{Conclusions}

The measurement and computer results suggest that: 1) including a gap filled with PBS increases thermal conductivity $(\mathrm{k})$ of trabecular bone by $0.02-0.04 \mathrm{Wm}^{-1} \mathrm{~K}^{-1}, 2$ ) the value of $\mathrm{k}$ is possibly around $0.36 \mathrm{Wm}^{-1} \mathrm{~K}^{-1}$ at $37^{\circ} \mathrm{C}$, with a temperature dependence of $+0.2 \%{ }^{\circ} \mathrm{C}^{-1}$, 3) the defatting process (i.e. replacing marrow by PBS) increases $\mathrm{k}$ by $0.04 \mathrm{Wm}^{-1} \mathrm{~K}^{-1}$, and 4) the presence of microstructure and fatty or red marrow has practically no effect on either maximum temperature or the position of the isotherms, which suggests that thermal models with a homogeneous geometry (i.e. ignoring the microstructure) can provide sufficiently accurate results.

\section{Acknowledgements}

This work was supported by a grant from the “Agencia Nacional de Promoción Científica y Tecnológica de Argentina” (Ref. PICT-2016-2303), and by the Spanish “Programa Estatal de Investigación, Desarrollo e Innovación Orientada a los Retos de la Sociedad" under Grant TEC2014-52383-C3-R (TEC2014-52383-C3-1-R). We thank Marisa Orzuza and Marcos Silbestro for assistance with the sample preparation and the circuit design. 


\section{References}

[1] Biyikli S, Modest MF, Tarr R. Measurements of thermal properties for human femora. Journal of Biomedical Materials Research Part A, 1986 20(9), 1335-1345.

[2] Bowman HF. Heat transfer and thermal dosimetry. 1981 J Microwave Power, 16(2), 121-133.

[3] Calttenburg R, Cohen J, Conner S, Cook N. Thermal properties of cancellous bone. J Biomed Materials Research Part A, 1975 9(2), 169-182.

[4] Collins CM, Liu W, Wang J, Gruetter R, Vaughan JT, Ugurbil K, Smith MB. Temperature and SAR calculations for a human head within volume and surface coils at 64 and $300 \mathrm{MHz}$. J Magnetic Resonance Imaging, 2004 19(5), 650-656.

[5] Cooper TE, Trezek GJ. Correlation of thermal properties of some human tissue with water content. 1971. Aerospace Medicine, 42(1), 24-27.

[6] Davidson SR, James DF. Measurement of thermal conductivity of bovine cortical bone. 2000. Med Eng Phys 22(10), 741-747.

[7] Davidson SR, James DF. Drilling in bone: modeling heat generation and temperature distribution. J Biomech Eng. 2003 Jun;125(3):305-14.

[8] Duck FA. Physical properties of tissue, a comprehensive reference book. 1990. London: Academic Press.

[9] El-Brawany MA, Nassiri DK, Terhaar G, Shaw A, Rivens I, Lozhken K. Measurement of thermal and ultrasonic properties of some biological tissues. 2009 J Med Eng Technol, 33(3), 249-256.

[10] Gee CS, Nguyen JT, Marquez CJ, Heunis J, Lai A, Wyatt C, Han M, Kazakia G, Burghardt AJ, Karampinos DC, Carballido-Gamio J, Krug R. Validation of bone marrow fat quantification in the presence of trabecular bone using MRI. J Magn Reson Imaging. 2015 Aug;42(2):539-44.

[11] Hansen E. Modelling heat transfer in a bone-cement-prosthesis system. J Biomech. 2003 Jun;36(6):787-95.

[12] Hasgall PA, Di Gennaro F, Baumgartner C, et al. "IT'IS Database for thermal and electromagnetic parameters of biological tissues,” Version 3.0, September 01st, 2015, doi: 10.13099/VIP21000-03-0. www.itis.ethz.ch/database. Accessed August 27, 2016. 
[13] Irastorza RM, Trujillo M, Martel Villagrán J, Berjano E. Computer modelling of RF ablation in cortical osteoid osteoma: Assessment of the insulating effect of the reactive zone. Int J Hyperthermia. 2016 May; 32(3):221-30. doi: 10.3109/02656736.2015.1135998.

[14] Kuyumcu G, Mason EG, Ilaslan H. Air-blocking ablation of osteoid osteoma; a technical note. Skeletal Radiol. 2017 Jul;46(7):957-960.

[15] Logg A, Mardal KA, Wells GN et al, Automated Solution of Differential Equations by the Finite Element Method. 2012 Springer, doi: 10.1007/978-3-642-23099-8.

[16] Li C, Kotha S, Huang CH, Mason J, Yakimicki D, Hawkins M. Finite element thermal analysis of bone cement for joint replacements. J Biomech Eng. 2003 Jun;125(3):315-22.

[17] Matschek J, Bullinger E, von Haeseler F, Skalej M, Findeisen R. Mathematical 3D modelling and sensitivity analysis of multipolar radiofrequency ablation in the spine. Math Biosci. 2017 Feb;284:5160. doi: 10.1016/j.mbs.2016.06.008.

[18] McIntosh RL, Anderson V. A comprehensive tissue properties database provided for the thermal assessment of a human at rest 2010 Biophysical Reviews and Letters, 5(03), 129-151.

[19] Poppendiek HF, Randall R, Breeden JA, Chambers JE, Murphy JR. Thermal conductivity measurements and predictions for biological fluids and tissues. 1967 Cryobiology, 3(4), 318-327.

[20] Rossmann C, Haemmerich D. Review of temperature dependence of thermal properties, dielectric properties, and perfusion of biological tissues at hyperthermic and ablation temperatures. 2014 Critical Review in Biomedical Engineering, 42(6), 467-492.

[21] Saha, S., and Williams, P. A. Effect of various storage methods on the dielectric properties of compact bone. Medical and Biological Engineering and Computing. 198826 (2), 199-202.

[22] Sierpowska J, Hakulinen MA, Töyräs J, Day JS, Weinans H, Kiviranta I, Jurvelin JS, Lappalainen R. Interrelationships between electrical properties and microstructure of human trabecular bone. 2006 Phys Med Biol. 21;51(20):5289-303.

[23] Sierpowska J, Lammi MJ, Hakulinen MA, Jurvelin JS, Lappalainen R, Töyräs J. Effect of human trabecular bone composition on its electrical properties. Med Eng Phys. 2007 Oct;29(8):845-52.

[24] Valvano JW, Cochran JR, Diller KR. Thermal conductivity and diffusivity of biomaterials measured with self-heated thermistors. Int J Thermophysics 1985 6(3), 301-311. 
[25] Van der Walt S, Schönberger JL, Nunez-Iglesias J, Boulogne F, Warner JD, Yager N, Gouillart E, Yu T and the scikit-image contributors. Scikit-image: Image processing in Python. PeerJ. 2014 2:e453.

[26] Zhang Y, Gan M, Tomar V. Raman thermometry based thermal conductivity measurement of bovine cortical bone as a function of compressive stress. Journal of Nanotechnology in Engineering and Medicine 2014 5(2), 021003-11. 
Table 1. Range of values of thermal conductivity $(\mathrm{k})$ of materials employed in computer model (assessed at $37^{\circ} \mathrm{C}$ ) (Hasgall et al 2005).

\begin{tabular}{|c|c|}
\hline Material & $k\left(\mathrm{~W} \mathrm{~m}^{-1} \mathrm{~K}^{-1}\right)$ \\
\hline Trabecular bone & $0.29-0.36$ \\
\hline Cortical bone & $0.30-0.36$ \\
\hline Bone marrow yellow & $0.19^{(1)}$ \\
\hline Bone marrow red & $0.28^{(1)}$ \\
\hline PBS (water) & 0.65 \\
\hline Air & 0.03 \\
\hline
\end{tabular}

${ }^{(1)}$ No range is given, simply a value. 
Table 2. Simulations plan and computer results.

\begin{tabular}{|c|c|c|c|c|c|c|}
\hline \multicolumn{5}{|c|}{ Simulations plan } & \multirow{2}{*}{\multicolumn{2}{|c|}{$\begin{array}{c}\text { Results } \\
k_{\text {eff }}\left(\mathrm{W} \mathrm{m}^{-1} \mathrm{~K}^{-1}\right)\end{array}$}} \\
\hline & \multicolumn{3}{|c|}{ Material assigned at each subdomain (see Table 1) } & \multirow[t]{2}{*}{ Purpose } & & \\
\hline & Bone matrix & Bone marrow & Gap & & & \\
\hline$\# 1$ & Cortical bone & Yellow bone marrow & Cortical bone & \multirow{2}{*}{$\begin{array}{l}\text { To compare with values reported for } k \\
\text { of trabecular bone }\end{array}$} & 0.30 & 0.35 \\
\hline$\# 2$ & Cortical bone & Red bone marrow & Cortical bone & & 0.31 & 0.36 \\
\hline \#3 & Cortical bone & Cortical bone & PBS & \multirow{3}{*}{$\begin{array}{c}\text { To assess the impact of PBS into the } \\
\text { gap, and compare 1,2,3 }\end{array}$} & 0.34 & 0.40 \\
\hline$\# 4$ & Cortical bone & Yellow bone marrow & PBS & & 0.32 & 0.37 \\
\hline \#5 & Cortical bone & Red bone marrow & PBS & & 0.33 & 0.39 \\
\hline \#6 & Cortical bone & Air & Cortical bone & $\begin{array}{c}\text { To compare with Clattenburg et al } \\
\text { after comparing with } 1\end{array}$ & 0.25 & 0.29 \\
\hline \#7 & Cortical bone & PBS (defatted) & PBS & To compare with our measurements & 0.37 & 0.43 \\
\hline
\end{tabular}

The two values reported for $k_{\text {eff }}$ correspond with two simulations in which the thermal conductivity of bone matrix was assumed to be 0.3 and $0.36 \mathrm{~W} \mathrm{~m}^{-1} \mathrm{~K}^{-1}$ (see Table 1 ). 
Table 3. Average ( \pm standard error) of measured values of thermal conductivity $\left(\mathrm{W} \mathrm{m} \mathrm{K}^{-1} \mathrm{~K}^{-1}\right)$ measured at three temperatures $(\mathrm{n}=20)$ under two conditions.

\begin{tabular}{|c|c|c|c|}
\hline Condition & $\mathbf{T}_{\text {LOW }}=\mathbf{3 7}{ }^{\circ} \mathbf{C}$ & $\mathbf{T}_{\text {LOW }}=\mathbf{4 7}{ }^{\circ} \mathbf{C}$ & $\mathbf{T}_{\text {LOW }}=\mathbf{5 7}{ }^{\circ} \mathbf{C}$ \\
\hline Non-defatted state & $0.39 \pm 0.06$ & $0.39 \pm 0.04$ & $0.41 \pm 0.07$ \\
\hline Defatted state & $0.43 \pm 0.05$ & $0.43 \pm 0.04$ & $0.44 \pm 0.06$ \\
\hline
\end{tabular}

During each measurement, the self-heated technique consisted of raising the temperature $4^{\circ} \mathrm{C}$ above $\mathrm{T}_{\mathrm{LOW}}$ and recording the power progress needed to achieve this increase. The thermal conductivity was assumed to be constant within this range of $4^{\circ} \mathrm{C}$. 

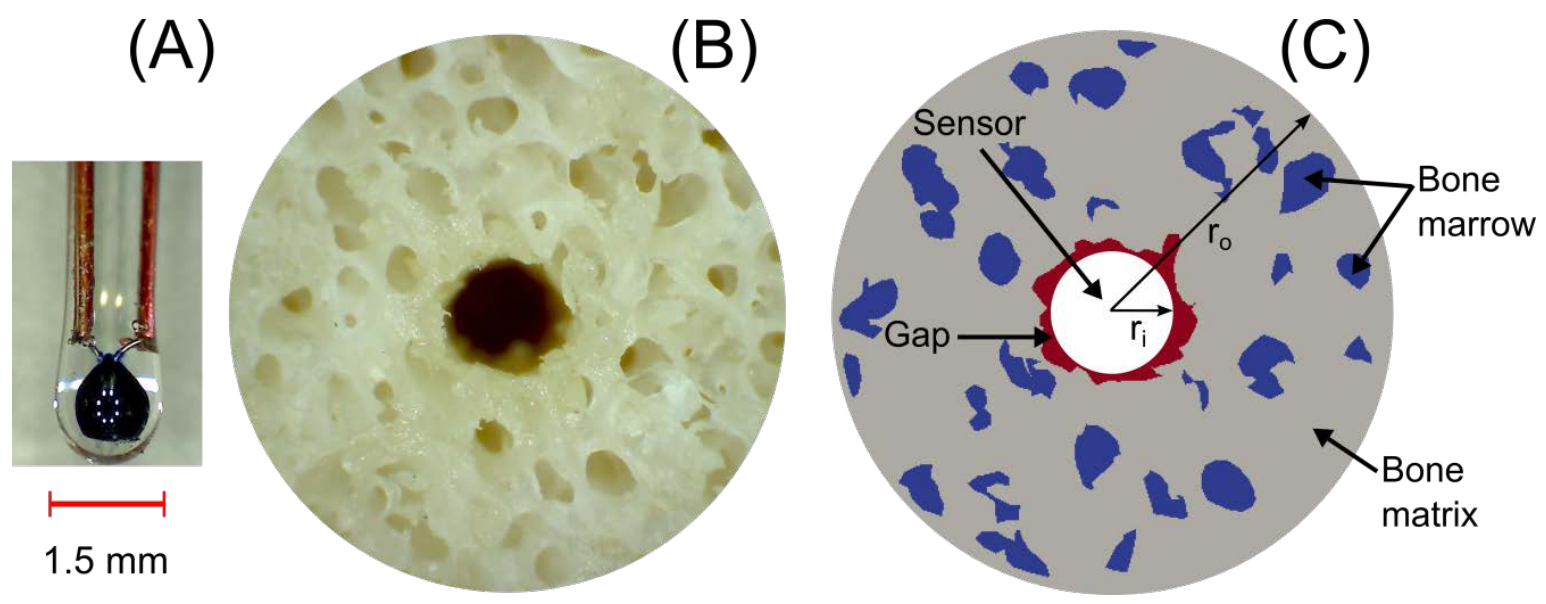

Figure 1 A: Thermistor used to measure thermal conductivity. B: Image of defatted sample (central hole for inserting thermistor. C: Geometry of the model based on the image (B), in which the red zone mimics the gap between thermistor and tissue, which fills with saline during the process. The central hole is not part of the model, and boundary conditions of constant temperature are set at the inner $\left(r_{i}\right)$ and outer $\left(r_{0}\right)$ limits of the model to mimic the performance of the self-heated thermistor during thermal measurements. 


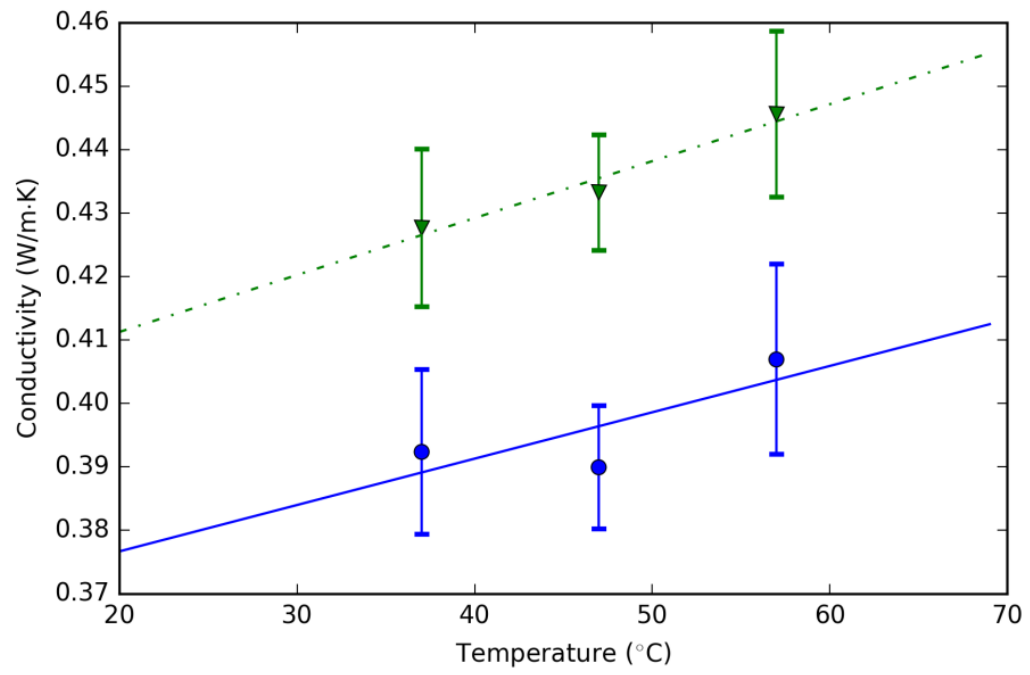

Figure 2 Effect of temperature on the thermal conductivity values measured in the samples of trabecular bone in two states: defatted (triangles) and non defatted (circles). The best-fit lines showed a slope of approximately $+0.2 \%\left({ }^{\circ} \mathrm{C}\right)^{-1}$. 

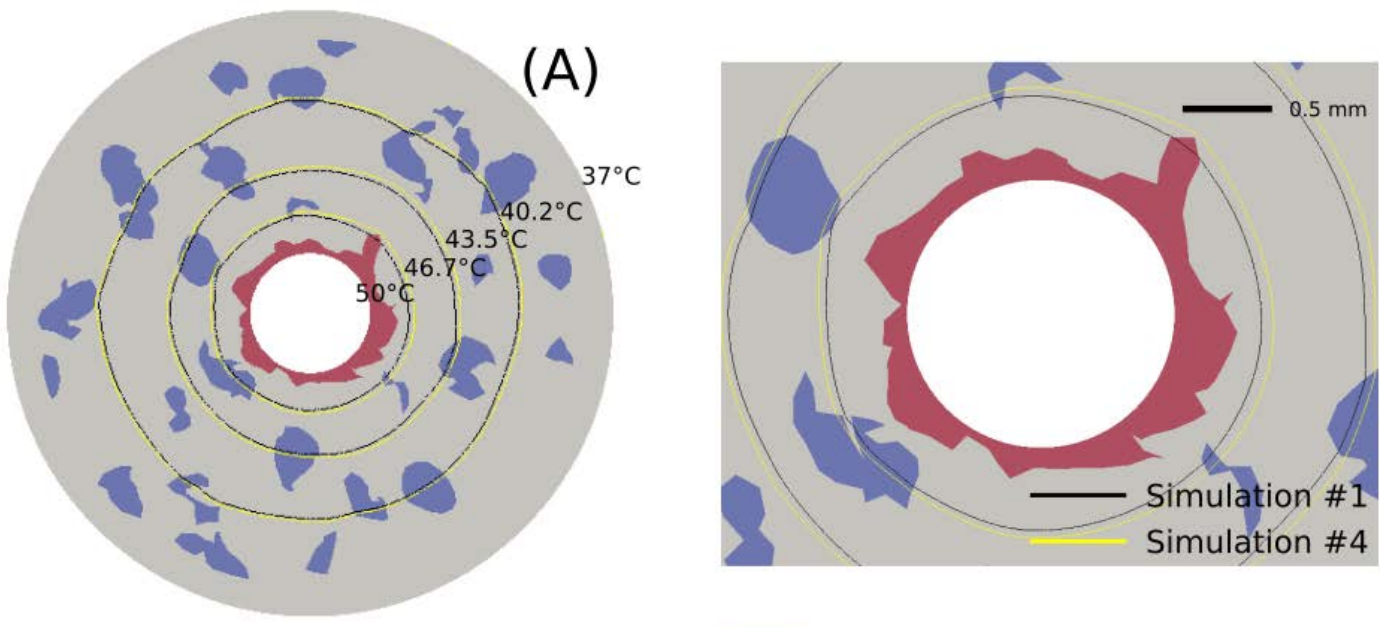

(B)

Difference of $\mathrm{T}\left({ }^{\circ} \mathrm{C}\right)$

$$
\begin{aligned}
& 0.70 \\
& -0.525 \\
& -0.35 \\
& -0.175 \\
& 0.00
\end{aligned}
$$

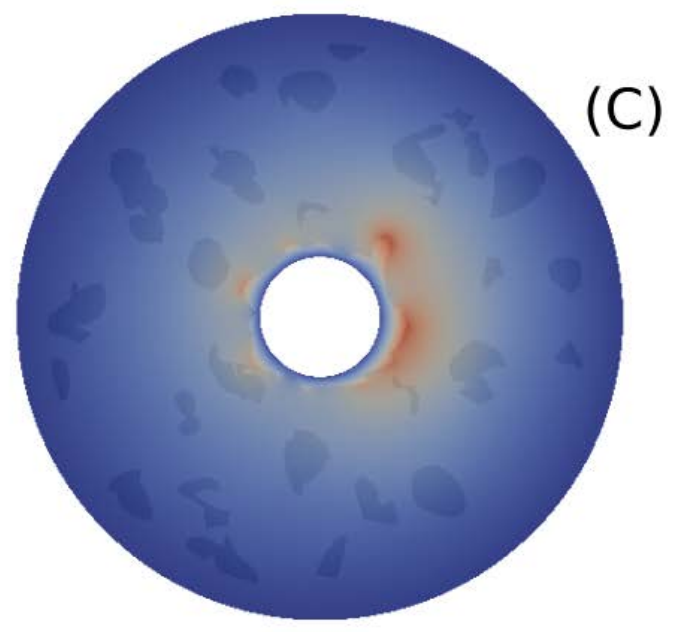

Figure 3 A and B: Spatial distributions of the isotherms obtained in the cases with (case \#4) and without (case \#1) a gap (red zone). The gap is assumed to be between the measuring probe (inserted into the central hole) and the bone tissue sample. C: Spatial distribution of the thermal differences $\left({ }^{\circ} \mathrm{C}\right)$ between both cases. 